\title{
ANALISIS PENGARUH GAYA KEPEMIMPINAN, PRAKTEK MANAJEMEN SDM TERHADAP KEPERCAYAAN PADA ORGANISASI DAN KEPUASAN KERJA KARYAWAN UNIVERSITAS AMIKOM PURWOKERTO
}

\author{
Akto Hariawan $^{1}$ dan Siti Barokah ${ }^{2}$ \\ ${ }^{1}$ Informatika \\ Fakultas Ilmu Komputer \\ Universitas Amikom Purwokerto \\ ${ }^{2}$ Bisnis Digital \\ Fakultas Bisnis dan Ilmu Sosial \\ Universitas Amikom Purwokerto \\ Email : akto.85@gmail.com¹, siti.barokah@amikompurwokerto.ac.id ${ }^{2}$
}

\begin{abstract}
ABSTRAK
Memiliki sumber daya manusia yang kompeten, berkarakter dan loyal merupakan bukti efektifitas kegiatan pemanfaatan sumber daya manusia yang berhasil dalam organisasi manajemen. Seorang pemimpin yang tidak memiliki keterampilan untuk menjaga kinerja dan kepuasan kerja adalah pemimpin yang tidak mempercayai bawahannya sesuai dengan peraturan yang berlaku. Tujuan dari penelitian untuk mengetahui pengaruh langsung gaya kepemimpinan dan praktik manajemen sumber daya manusia terhadap kepercayaan organisasi dan kepuasan kerja karyawan. Sampel dalam penelitian ini adalah 30 pegawai Universitas Amikom Purwokerto. Variabel yang digunakan dalam penelitian ini adalah gaya kepemimpinan, praktik manajemen sumber daya manusia, kepercayaan pada organisasi, dan kepuasan kerja karyawan. Hasil penelitian menunjukkan bahwa gaya kepemimpinan dan praktek manajemen berpengaruh positif terhadap kepercayaan pada organisasi, dan kedua, kepercayaan organisasi berpengaruh positif terhadap kepuasan kerja karyawan.
\end{abstract}

Kata Kunci: Gaya kepemimpinan, praktek manajemen SDM, kepercayaan, kepuasan kerja

\begin{abstract}
Having competent, character and loyal human resources is evidence of the effectiveness of successful human resource utilization activities in management organizations. A leader who does not have the skills to maintain performance and job satisfaction is a leader who does not trust his subordinates in accordance with applicable regulations. The purpose of this study was to determine the direct effect of leadership style and human resource management practices on organizational trust and employee job satisfaction. The sample in this study were 30 employees of the University of Amikom
\end{abstract}


Purwokerto. The variables used in this study are leadership style, human resource management practices, trust in the organization, and employee job satisfaction. The results showed that leadership style and management practices had a positive effect on organizational trust, and second, organizational trust had a positive effect on employee job satisfaction.

Keywords: Leadership style, human resource management practice, trust, job satisfaction

\section{PENDAHULUAN}

Untuk mencapai tujuan tertentu, suatu organisasi memerlukan manajemen sumber daya manusia (SDM), yang terutama mencakup perencanaan, penarikan, pemilihan, pengembangan dan pemeliharaan, serta penggunaan sumber daya. Tujuan yang ingin dicapai adalah tujuan pribadi dan tujuan organisasi. Adanya pengelolaan SDM yang baik memberikan kepuasan kerja bagi karyawan. Oleh karena itu, kepuasan karyawan dapat dipengaruhi oleh kepercayaan (Aryee et al., 2004).

Menurut (Moorman et al., 1993) sikap ketidakmauan untuk menyandarkan diri pada partner atas dasar ketidakyakinan disebut dengan tidak percaya. Sedangkan, sikap seseorang untuk meyakini sesuatu dengan berbagai pertimbangan yang matang untuk memahami dan meyakini hal yang dilakukannya maka hal tersebut dapat dikatakan sebagai kepercayaan. Pernyataan tersebut didukung dengan pernyataan (Morgan \& Hunt, 1994) bahwa pada saat satu pihak memiliki keyakinan maka disitulah kepercayaan itu muncul. Penelitian (Utama \& Sintaasih, 2015) menemukan bahwa kepuasan kerja, turnover intentions, dan komitmen organisasi dipengaruhi oleh adanya kepercayaan.

Penelitian yang dilakukan oleh (Mu'iz \& Muchsinati, 2017) menemukan bahwa praktek manajemen SDM (selektif staf, promosi praktis, keamanan kerja, keadilan reward, pelatian berkesinambungan, keikutsertaan dalam membuat keputusan, komunikasi dan penilain perkembangan dan gaya kepemimpinan) mempunyai pengaruh terhadap kepercayaan. 
Kepemimpinan merupakan faktor penting dalam menentukan kemampuan organisasi dalam beradaptasi dengan perubahan lingkungan serta menentukan kinerja karyawan (Harahap, 2016). Menurut (Rivai \& Mulyadi, 2013) kesanggupan untuk berbuat baik, sikap, gerakan, gerak gerik yang bagus, tingkah laku serta kekuatan merupakan sekumpulan ciri dari gaya. Dalam menjalankan organisasi, pemimpin memiliki gaya kepemimpinan sendiri. Sehingga, gaya kepemimpinan lebih berfokus pada hal-hal yang dilakukan oleh setiap pemimpin.

(Kerfoot, 2019) menyatakan bahwa gaya kepemimpinan mempunyai hubungan dengan kepercayaan. Pernyataan tersebut didukung oleh (Arifudin, 2020) yang menemukan adanya pengaruh langsung antara kedua variabel tersebut. Jika gaya kepemimpinan meningkat maka kepercayaan terhadap organisasi meningkat pula. Penelitian ini berusaha mengembangkan yang terjadi pada penelitian sebelumnya, yaitu pada penelitian (Mathebula, 2014) di institusi pendidikan dan berlokasi di afrika selatan, sedangkan penelitian ini bertempat di institusi pendidikan yaitu Universitas Amikom Purwokerto dengan menambahkan kepuasan kerja sesuai penelitian (Farida et al., 2016) yang penelitiannya menemukan bahwa kepuasan kerja dipengaruhi oleh kepercayaan. Berdasarkan hasil penelitian terdahulu, penulis meneliti mengenai pengaruh langsung gaya kepemimpinan dan praktik MSDM pada kepercayaan terhadap organisasi serta kepuasan kerja di Universitas Amikom Purwokerto.

\section{METODE PENELITIAN}

Pendekatan kuantitatif menggunakan angka dari proses pengumpulan, interpretasi dan pemaparan hasil (Sumiharyati \& Arikunto, 2019). Karyawan Universitas Amikom Purwokerto merupakan populasi dalam penelitian ini. Pengujian variabel menggunakan analisis regresi. Data primer digunakan dalam penelitian ini dengan menyebarkan kuesioner kepada responden. Likert scale 5 (lima) poin digunakan dalam penelitian ini untuk mengukur tanggapan negatif maupun tanggapan positif dari suatu pernyataan yang diberikan. 


\section{HASIL DAN PEMBAHASAN}

1. Uji Validitas

Uji validitas dengan membagikan kepada 30 responden. Tabel 1 merupakan hasil uji validitas instrumen yang telah dilakukan. Diketahui bahwa instrumen dalam variabel gaya kepemimpinan, praktek manajemen SDM, kepercayaan terhadap organisasi, dan kepuasan kerja adalah valid. Karena, masing-masing item memiliki nilai r-hitung $\geq$ r-tabel yaitu $(0,361)$.

Tabel 1. Uji Validitas

\begin{tabular}{|c|c|c|c|c|c|c|c|}
\hline \multicolumn{2}{|c|}{$\begin{array}{c}\text { Gaya } \\
\text { Kepemimpinan }\end{array}$} & \multicolumn{2}{c|}{ Praktek MSDM } & \multicolumn{2}{c|}{$\begin{array}{c}\text { Kepercayaan } \\
\text { terhadap } \\
\text { Organisasi }\end{array}$} & \multicolumn{2}{c|}{ Kepuasan Kerja } \\
\hline Item & R hitung & Item & R-hitung & Item & R-hitung & Item & R-hitung \\
\hline 1 & 0,519 & 1 & 0,575 & 1 & 0,530 & 1 & 0,573 \\
\hline 2 & 0,553 & 2 & 0,560 & 2 & 0,586 & 2 & 0,643 \\
\hline 3 & 0,530 & 3 & 0,572 & 3 & 0,433 & 3 & 0,640 \\
\hline 4 & 0,580 & 4 & 0,521 & 4 & 0,703 & 4 & 0,502 \\
\hline 5 & 0,539 & 5 & 0,531 & 5 & 0,540 & 5 & 0,635 \\
\hline 6 & 0,552 & 6 & 0,548 & 6 & 0,712 & 6 & 0,683 \\
\hline 7 & 0,623 & 7 & 0,538 & & & 7 & 0,702 \\
\hline 8 & 0,552 & 8 & 0,619 & & & 8 & 0,604 \\
\hline 9 & 0,543 & & & & & & \\
\hline 10 & 0,581 & & & & & & \\
\hline
\end{tabular}

2. Uji Reliabilitas

Konsistensi instrumen penelitian diuji dengan reliabilitas. Tabel 2 merupakan hasi uji reliabilitas. Nilai Cronbach's Alpha variabel gaya kepemimpinan adalah 0,751, praktek manajemen SDM adalah 0,684, kepercayaan terhadap organisasi adalah 0,607, dan kepuasan kerja sebesar 0,777. Hal tersebut menunjukkan bahwa nilainya diatas 0,6 yang berarti seluruh variabel reliabel.

Tabel 2. Hasil Uji Reliabilitas

\begin{tabular}{|l|c|c|}
\hline \multicolumn{1}{|c|}{ Nama Variabel } & Cronbach's Alpha & N of Items \\
\hline Gaya Kepemimpinan & 0,751 & 10 \\
\hline Praktek MSDM & 0,684 & 8 \\
\hline Kepercayaan terhadap Organisasi & 0,607 & 6 \\
\hline Kepuasan Kerja & 0,777 & 8 \\
\hline
\end{tabular}


3. Koefisien Determinasi $\left(\mathrm{R}^{2}\right)$

Hasil uji Adjusted R-Square disajikan dalam tabel 3 dan 4. Berdasarkan tabel 3 Adjusted $R^{2}$ memiliki nilai yaitu 0,761 . Artinya 76,1\% kepercayaan terhadap organisasi mampu dijelaskan oleh gaya kepemimpinan dan praktik manajemen SDM sementara 23,9\% dijelaskan oleh variabel lain namun tidak dimasukkan dalam penelitian.

Tabel 3. Adjusted R-Square 1

\begin{tabular}{|l|c|c|c|c|}
\hline \multicolumn{5}{|c|}{ Model Summary } \\
\hline Model & $R$ & $\begin{array}{c}R \\
\text { Square }\end{array}$ & $\begin{array}{c}\text { Adjusted } R \\
\text { Square }\end{array}$ & $\begin{array}{c}\text { Std. Error of the } \\
\text { Estimate }\end{array}$ \\
\hline 1 & 0.879 & 0.773 & 0.761 & 1.37341 \\
\hline $\begin{array}{l}\text { a. Predictors: } \\
\text { Kepemimpinan }\end{array}$ & Constant), Praktek Manajemen SDM, Gaya \\
\hline
\end{tabular}

Tabel 4. Adjusted R-Square 2

\begin{tabular}{|l|c|c|c|c|}
\hline \multicolumn{5}{|c|}{ Model Summary } \\
\hline Model & $R$ & $\begin{array}{c}R \\
\text { Square }\end{array}$ & $\begin{array}{c}\text { Adjusted } R \\
\text { Square }\end{array}$ & $\begin{array}{c}\text { Std. Error of the } \\
\text { Estimate }\end{array}$ \\
\hline 1 & $0.677^{\mathrm{a}}$ & 0.458 & 0.444 & 2.29219 \\
\hline \multicolumn{2}{|c|}{ Predictors: (Constant), Kepercayaan } \\
\hline
\end{tabular}

Dari tabel 4 diketahui juga Adjusted $R^{2}$ memiliki nilai yaitu 0,444 yang artinya adalah 44,4\% kepuasan kerja karyawan Universitas Amikom Purwokerto dapat dijelaskan oleh variabel kepercayaan terhadap organisasi. Sedangkan $55,6 \%$ dipengaruhi variabel lain yang tidak termasuk di dalam model penelitian.

4. Analisis Regresi Berganda

Untuk menguji pengaruh gaya kepemimpinan dan praktek manajemen SDM terhadap kepercayaan pada organisasi, maka dilakukan analisis regresi berganda.

Tabel 5. Regresi Linear Berganda

\begin{tabular}{|l|c|c|c|c|}
\hline \multicolumn{5}{|c|}{ Persamaan } \\
\hline \multirow{3}{*}{ Variabel Independen } & \multicolumn{4}{|c|}{$\begin{array}{c}\text { Variabel Dependen } \\
\text { Kepercayaan }\end{array}$} \\
\cline { 2 - 5 } & Koefisien & t hitung & t tabel & Sig. \\
\hline Gaya Kepemimpinan & 0,301 & 5,104 & 2,056 & $0,000^{*}$ \\
\hline Praktek MSDM & 0,406 & 5,394 & 2,056 & $0,000^{*}$ \\
\hline
\end{tabular}

*) Signifikan pada level 5\% 
Berdasarkan tabel 5, gaya kepemimpinan berpengaruh positif pada kepercayaan karyawan organisasi. Koefisien gaya kepemimpinan menunjukkan angka 0,301 dan signifikansinya adalah $0,000 \leq 0,05$ atau thitung sebesar 5,104 $\geq$ ttabel 2,056. Variabel manajemen SDM diketahui juga berpengaruh positif pada kepercayaan pada organisasi dengan nilai koefisien yaitu 0,406 dengan signifikansinya 0,000 $\leq 0,05$ atau thitung sebesar 5,394 $\geq$ ttabel 2,056.

Gaya kepemimpinan berpengaruh positif pada kepercayaan, hal ini berarti bahwa ketika para pemimpin di Universitas Amikom Purwokerto mampu memberikan contoh teladan, memiliki kemampuan dalam memahami dan mengimplementasikan visi misi organisasi serta strategi dalam mengembangkan organisasi akan menumbuhkan tingkat kepercayaan para karyawan di Universitas Amikom Purwokerto. Ketika pemimpin pada saat berinteraksi dengan bawahannya menggunakan suatu cara yang positif dan tepat seperti kepemimpinan transaksional, kepemimpinan transformasional dan kepemimpinan yang menyerahkan segala sesuatunya kepada bawahannya atau yang biasa disebut dengan kepemimpinan laissez faire ((Tjiptono, 2016); (Yammarino et al., 1993)). Sehingga, dengan cara yang positif dan tepat tersebut nantinya dapat menumbuhkan kepercayaan antara bawahan terhadap seorang pemimpin pada organisasi. Sebaliknya, ketika para pemimpin di Universitas Amikom memiliki gaya kepemimpinan yang tidak tepat maka hal ini akan menurunkan tingkat kepercayaan pada organisasi yaitu Universitas Amikom Purwokerto.

Praktek manajemen SDM juga berpengaruh positif pada kepercayaan organisasi. Semakin baik praktik manajemen SDM di sebuah organisasi maka hal ini akan mampu meningkatkan kepercayaan pada organisasi. Praktek manajemen SDM dapat dilakukan dengan mengamati kondisi eksternal untuk menunjukkan praktek manjemen SDM yang lebih khusus (Cater et al., 2019). Selanjutnya, dilakukan kerjasama, mengadakan pelatihan dan pengembangan, memberikan insentif, dan memberikan keamanan baik dalam produktivitas maupun fleksibilitas kinerja karyawan (Hom et al., 2017). Sebaliknya, ketika sebuah 
organisasi tidak memiliki praktik manajemen SDM yang baik, maka hal ini akan menurunkan tingkat kepercayaan pada organisasi.

5. Analisis Regresi Sederhana

Hubungan kausal kepercayaan pada organisasi terhadap kepuasan kerja menggunakan regresi sederhana ditampilkan pada tabel 6. Kepercayaan organisasi berpengaruh positif pada kepuasan kerja. Kepercayaan organisasi menunjukkan nilai koefisien yaitu 0,740 dengan tingkat signifikansinya yaitu $0,000 \leq 0,05$ atau thitung sebesar 5,667 $\geq$ ttabel 2,056.

Tabel 6. Regresi Linear Sederhana

\begin{tabular}{|l|c|c|c|c|}
\hline \multicolumn{5}{|c|}{ Persamaan Regresi Linier Sederhana } \\
$Y=14,745+0,740 \mathrm{X}$ \\
\hline \multirow{4}{*}{ Variabel Independen } & \multicolumn{4}{|c|}{ Variabel Dependen } \\
& & Kepuasan Kerja \\
\cline { 2 - 5 } & Koefisien & t hitung & t tabel & Sig. \\
\hline Kepercayaan & 0,740 & 5,667 & 2,056 & $0,000^{*}$ \\
\hline
\end{tabular}

Kepercayaan berpengaruh positif pada kepuasan kerja. Ketika tingkat kepercayaan semakin tinggi pada organisasi maka kepuasan kerja karyawan tersebutpun tinggi. Sebaliknya, karyawan pada organisasi yang memiliki tingkat kepercayaan yang rendah maka karyawan tersebut memiliki kepuasan kerja yang rendah pada organisasi. Hal ini dikarenakan ketika tidak ada kepercayaan, maka organisasi tidak akan berfungsi dan berjalan secara baik (Whitener et al., 1998). Selain itu, ketika di dalam sebuah organisasi tidak terdapat keharmonisan interaksi, maka tidak ada kesuksesan interaksi antar individu baik di luar maupun di dalam organisasi ((Utaminingsih, 2017); (Mitchell et al., 2018)).

\section{KESIMPULAN DAN SARAN}

Berdasarkan penelitian yang dilakukan dapat ditarik kesimpulan bahwa gaya kepemimpinan dan praktik manajemen SDM berpengaruh positif pada kepercayaan organisasi. Semakin baik gaya kepemimpinan dan praktik manajemen SDM yang diterapkan di suatu organisasi maka tingkat kepercayaan pada organisasi tersebut juga akan meningkat. Sehingga, semakin tinggi kepercayaan pada organisasi, 
seorang karyawan juga merasa memiliki kepuasan kerja yang tinggi di organisasi. Penelitian selanjutnya dapat ditambahkan dengan variabel motivasi dan budaya organisasi untuk meningkatkan kepercayaan pada organisasi dan kepuasan kerja karyawan.

\section{DAFTAR PUSTAKA}

Arifudin, O. (2020). Pengaruh Gaya Kepemimpinan Transformasional. 4(3), 178187.

Aryee, S., Chen, Z. X., \& Budhwar, P. S. (2004). Exchange fairness and employee performance: An examination of the relationship between organizational politics and procedural justice. Organizational Behavior and Human Decision Processes, 94(1), 1-14. https://doi.org/10.1016/j.obhdp.2004.03.002

Cater, J., James, K., Kidwell, R., Camp, K., \& Young, M. (2019). HRM practices and effectiveness: a comparison of US Hispanic and non-Hispanic family firms. Journal of Small Business and Enterprise Development, 26(5), 726746. https://doi.org/10.1108/JSBED-12-2018-0364

Farida, S. I., Iqbal, M., \& Kurniasih, A. (2016). Pengaruh Kepercayaan Dan Komitmen Organisasi Terhadap Motivasi Kerja Serta Implikasinya Pada Kepuasan Kerja. Jurnal Kependidikan: Penelitian Inovasi Pembelajaran, $121-134$.

Harahap, S. (2016). Pengaruh Kepemimpinan Islami dan Motivasi Kerja Terhadap Kinerja Karyawan Pada PT . Bank Syariah Mandiri, Tbk. 3(2).

Hom, P. W., Lee, T. W., Shaw, J. D., \& Hausknecht, J. P. (2017). One hundred years of employee turnover theory and research. Journal of Applied Psychology, 102(3), 530-545. https://doi.org/10.1037/apl0000103

Kerfoot, K. M. (2019). On Leadership Chaos, Teamwork, Compassion, and Leadership: Disasters and Nursing's Finest Hours. 37(5), 265-267.

Mitchell, R. M., Kensler, L., \& Tschannen-Moran, M. (2018). Student trust in teachers and student perceptions of safety: positive predictors of student identification with school. International Journal of Leadership in Education, 21(2), 135-154. https://doi.org/10.1080/13603124.2016.1157211

Moorman, C., Deshpande, R., \& Zaltman, G. (1993). Factors Affecting Trust in Market Research Relationships. Journal of Marketing, 57(1), 81. https://doi.org/10.2307/1252059

Morgan, R. M., \& Hunt, S. D. (1994). The Commitment-Trust Theory of. Journal of Marketing, 58(July), 20-38. https://journals.sagepub.com/doi/full/10.1177/002224299405800302 
Mu'iz, A., \& Muchsinati, E. S. (2017). Analisis pengaruh praktik manajemen sumber daya manusia terhadap kinerja karyawan (Studi kasus pada hotel bintang empat di Batam). Journal of Accounting \& Management Innovation, 1(1), 49-63.

Rivai, V.Z., \& Mulyadi, D. (2013). Islamic Management. BPFE: Yogyakarta.

Sumiharyati, S., \& Arikunto, S. (2019). Evaluasi program in-service training guru SMK di BLPT Yogyakarta. Jurnal Akuntabilitas Manajemen Pendidikan, 7(2), 160-173. https://doi.org/10.21831/amp.v7i2.26654

Tjiptono. (2016). Kepemimpinan. Bayu Media: Malang.

Utama, D. G. A. S., \& Sintaasih, D. K. (2015). PENGARUH WORK - FAMILY CONFLICT DAN KEPUASAN KERJA TERHADAP KOMITMEN ORGANISASIONAL DAN TURNOVERINTENTION Fakultas Ekonomi dan Bisnis Universita s Udayana, Bali, Indonesia Fakultas Ekonomi dan Bisnis Universitas Udayana, Bali, Indonesia ABSTRAK PENDAH. 4(11), 37033734.

Utaminingsih, B. A. (2017). Structural model of organizational culture dimension and contingency leadership style in shaping organizational trust and commitment of private university lecturers. 10-23.

Whitener, E. M., Brodt, S. E., Korsgaard, M. A., \& Werner, J. M. (1998). Managers as Initiators of Trust: An Exchange Relationship Framework for Understanding Managerial Trustworthy Behavior. The Academy of Management Review, 23(3), 513. https://doi.org/10.2307/259292

Yammarino, F. J., Spangler, W. D., \& Bass, B. M. (1993). Transformational leadership and performance: A longitudinal investigation. The Leadership Quarterly, 4(1), 81-102. https://doi.org/10.1016/1048-9843(93)90005-E 